GHANA JOURNAL OF DEPARTMENT OF HEALTH, PHYSICAL EDUCATION AND RECREATION, SPORTS AND DANCE (GJOHPERSD)

\author{
Volume 9, Year 2016
}

A JOURNAL OF THE DEPARTMENT OF HEALTH, PHYSICAL EDUCATION AND RECREATION (HPER)

UNIVERSITY OF CAPE COAST

GHANA, WEST AFRICA 


\title{
OPTIMIZING MOTOR SKILLS THROUGH CLASSICAL CONDITIONING THEORY
}

\author{
Elvis I. Agbonlahor \& Kelly Osasehia Eghosa \\ Department of Human Kinetics and Sports Science, University Of \\ Benin, Benin City
}

\begin{abstract}
Over the years, experts have sought varied means of enhancing the learning of motor skills and optimizing motor performance. The role of learning theories in the learning of motor skills has been studied. Classical conditioning is a reflexive or automatic type of learning in which a stimulus acquires the capacity to evoke a response that was originally evoked by another stimulus. This study explains the role of classical conditioning on motor learning and performance. Classical conditioning should be applied in the teaching of the practical aspects of physical education to students especially in the early stages of their learning. This would help in motivating them and consequently optimizing their motor skill learning and performance. One must be able to practice and master a task effectively before embarking on another one. This means that a student needs to be able to respond to a particular stimulus (information) before he/she can be associated with a new one. Classical conditioning should be used by Coaches and Sports Psychologists in helping Athletes overcome their fear of failure or opponents. There is the need for more studies on the optimizing of motor outcomes via classical conditioning to be conducted.
\end{abstract}

Keywords: Motor Skills, Classical Conditioning, Stimulus, Response 


\section{Introduction}

A theory is a set of generalized statements supported by experimental evidence. It is based on the preliminary findings of previous researchers. Several theories have therefore evolved about how people learn. While some theories are better than others in explaining types of learning. However, no particular or single theory is sufficient to explain how all learning takes place. Classical conditioning is a reflexive or automatic type of learning in which a stimulus acquires the capacity to evoke a response that was originally evoked by another stimulus. It is sometimes referred to as "Pavlovian" conditioning and was developed by Ivan Pavlov a Russian physician and researcher who did a lot of important work studying the digestive system. Pavlov redirected the animal's digestive fluids outside the body, where they could be measured and noticed that his dogs began to salivate in the presence of the technician who normally fed them, rather than simply salivating in the presence of food. Pavlov called the dogs' anticipatory salivation "psychic secretion." Putting these informal observations to an experimental test, Pavlov presented a stimulus (e.g. the sound of a metronome) and then gave the dog food; after a few repetitions, the dogs started to salivate in response to the stimulus. Pavlov concluded that if a particular stimulus in the dog's surroundings was present when the dog was given food then that stimulus could become associated with food and cause salivation on its own. He called the stimulus the conditioned (or conditional) stimulus (CS) because its effects depend on its association with food (Douglas, Brian \& Arthur, 2009). He called the food the unconditioned stimulus (US) because its effects did not depend on previous experience. Likewise, the response to the CS was the conditioned response (CR) and that to the US was the unconditioned response (UR). Pavlov reported many basic facts about conditioning; for example, he found that learning occurred most rapidly when the interval between the conditioned stimulus and the appearance of the unconditioned stimulus was relatively short (Brink, 2008). 
Elvis I. Agbonlahor \& Kelly Osasehia Eghosa

Classical conditioning occurs when a conditioned stimulus is paired with an unconditioned stimulus. Usually, the conditioned stimulus (CS) is a neutral stimulus (e.g the sound of a tuning fork), the unconditioned stimulus (US) is biologically potent (e.g the taste of food) and the unconditioned response (UR) to the unconditioned stimulus is an unlearned reflex response (e.g., salivation). After pairing is repeated (some learning may occur after only one pairing), the organism exhibits a conditioned response (CR) to the conditioned stimulus when the conditioned stimulus is presented alone. The conditioned response is usually similar to the unconditioned response, but unlike the unconditioned response, it must be acquired through experience and is relatively impermanent (Cherry \& Kendra, 2003). In classical conditioning, the conditioned stimulus is not simply connected to the unconditioned response; the conditioned response usually differs in some way from the unconditioned response, sometimes significantly. For this and other reasons, learning theorists commonly suggest that the conditioned stimulus comes to signal or predict the unconditioned stimulus, and go on to analyze the consequences of this signal (Shettleworth, 2010).

A basic characteristic of classical conditioning, in comparison to another popular model, operant conditioning, is that the learning is automatic and non-conscious. Pavlov identified four basic components in this classical conditioning model. The unconditioned stimulus is the stimulus that naturally and instinctively elicits the target response, which, in the case of his classic experiment is the meat powder. The conditioned stimulus is the stimulus that comes to elicit the target response, which was the tone in Pavlov's experiment. The unconditioned and conditioned responses are a little trickier to identify in that they are often the exact same behavior. For example in Pavlov's experiment they are both salivation. The fundamental difference is that the unconditioned response occurs as a result of the unconditioned stimulus, and the conditioned response occurs in response to the conditioned stimulus. In Pavlov's experiment, the unconditioned response is salivation in response to the meat powder, and the 
Optimizing motor skills through classical conditioning theory

conditioned response is salivation in response to the tone. One special and very powerful example of classical conditioning is taste aversion. Taste aversion is a case where an organism learns to have an aversion to the taste or smell or other characteristics of some food or drink. For example, after consuming too much alcohol, it's not unusual for someone to associate the smell or even sight of the alcohol with the sickness that resulted from consuming the alcohol.

While Ivan Pavlov showed that classical conditioning applied to animals, Watson and Rayner (1920) in a famous (though ethically dubious) experiment showed that it also applies to humans. They performed their experiment on a 9-month-old infant "Little Albert" who was tested on his reactions to various stimuli. He was shown a white rat, a rabbit, a monkey and various masks. Albert described as "on the whole stolid and unemotional" showed no fear of any of these stimuli. However, what did startle him and cause him to be afraid was if a hammer was struck against a steel bar behind his head. The sudden loud noise would cause "little Albert to burst into tears. When Little Albert was just over 11 months old the white rat was presented and seconds later the hammer was struck against the steel bar. This was done 7 times over the next 7 weeks and each time Little Albert burst into tears. By now little Albert only had to see the rat and he immediately showed every sign of fear. He would cry (whether or not the hammer was hit against the steel bar) and he would attempt to crawl away. In addition, Watson and Rayner found that Albert developed phobias of objects which shared characteristics with the rat; including the family dog, a fur coat, some cotton wool and a Father Christmas mask! This process is known as generalization. Watson and Rayner had shown that classical conditioning could be used to create a phobia. A phobia is an irrational fear, i.e. a fear that is out of proportion to the danger. Over the next few weeks and months Little Albert was observed and 10 days after conditioning his fear of the rat was much less marked. This dying out of a learned response is called extinction. However, even after a full month it was still evident, and the association could be 
renewed by repeating the original procedure a few times. If for example a college student instinctively fears tests and is taking a general psychology class in which the instructor always wears a black jacket on test day. Thus, the black jacket eventually comes to serve as a conditioned stimulus in that it elicits fear in the student, independent of the test. For the record, this last example is actually a "second order" classical conditioning in that in "pure" classical conditioning, the unconditioned stimulus - unconditioned response contingency should be basic and instinctive. Students don't actually have an instinctual fear of tests; rather, this is something that is itself classically conditioned at an earlier age. However, note one important thing about all these examples, which is that they all involve a target/learned behavior that is non conscious and basic, usually involving some response of the autonomic nervous system (e.g., fear, sadness, anxiety, excitement, or joy).

\section{Characteristics of Classical Conditioning}

There are, different variables that can affect the degree to which classical conditioning will or will not occur in different situations. The study of classical conditioning can become quite complex through the consideration of these different variables, and learning researchers have examined many over the years. One of such variables is the time difference between the conditioned stimulus and the unconditioned stimulus which is referred to as latency. Worthy of note is that the conditioned stimulus is supposed to come first. For example, if Pavlov always sounded the tone after the dog got meat powder, the tone, in the absence of the meat powder, would signal that the dog somehow missed getting it's meat powder so, in fact, it might as well not salivate. Given that the conditioned stimulus does precede the unconditioned stimulus, the general rule of thumb is that the shorter the latency the more likely it is that the conditioning will occur. Another interesting phenomenon that Pavlov identified was a phenomenon now known as "spontaneous recovery". This is the re-occurrence of a classically conditioned response after extinction has occurred. Extinction refers to the fact, that, if the conditioned and 
Optimizing motor skills through classical conditioning theory

unconditioned stimuli are not paired for a given number of trials an organism will stop exhibiting the conditioned response. For example, the student mentioned above will, perhaps, some day come to really like black jackets again. However, after he or she has gotten over the fear of black jackets, the fear may suddenly reappear. This would be spontaneous recovery. A final important characteristic of classical conditioning is referred to as generalization. This is the case where stimuli that are like the conditioned stimulus come to elicit the same response. A classic example is "Little Albert" allegedly became fearful of other animals and even his Mother's fur coat.

John Watson proposed that the process of classical conditioning (based on Pavlov's observations) was able to explain all aspects of human psychology. Everything from speech to emotional responses were simply patterns of stimulus and response. Watson denied completely the existence of the mind or consciousness. He believed that all individual differences in behavior were due to different experiences of learning. He famously said:

"Give me a dozen healthy infants, well-formed, and my own specified world to bring them up in and I'll guarantee to take any one at random and train him to become any type of specialist I might select - doctor, lawyer, artist, merchant-chief and, yes, even beggar-man and thief, regardless of his talents, penchants, tendencies, abilities, vocations and the race of his ancestors" (Watson, 1924, p.104).

\section{Learning}

Burns (1995) regards learning as a relatively permanent change in behaviour, which includes both observable activity and internal processes such as thinking, attitudes and emotions. Learning occurs right from the birth of the child and proceeds until he/she dies. Learning is acquired due to the prior experience one has gained. A child may learn from his/her environment (teacher) consciously or unconsciously, and in the process, his/her behaviour is being modified either negatively or positively. However, the 
Elvis I. Agbonlahor \& Kelly Osasehia Eghosa essence of enrolling in the school by the students is to acquire desirable/positive behaviour under the tutelage of the teacher. To this end, learning can be described as a process by which an individual:

1. Aquires a novel idea or experience to a situation.

2. Retains and applies the idea, skills and knowledge in solving the confronting problems.

3. Modify one's behaviour by the experience gained in the past and making the change permanent.

In view of the above points, learning is considered as:

1. A relatively permanent change in behavior.

2. Not just a visible but also manifest responses of the learner

3. Modifying the learner's behaviour.

4. Being dependent on previously acquired experience.

Some behaviour cannot be described as being learnt because they occur at the moment of anatomical maturation. This type of learning occurs as one matures physically. For example, a child does not learn how to walk, eat or talk but acquires these skills as he/she advances in age. This behaviour is regarded as "speciespecific behaviour" (Ayeni, 1991).

\section{The Concept of Motor Learning}

Motor learning is the acquisition, completion and utilization of motor information, knowledge, experience, and motor programmes (Adams, 1976). It is closely connected with mental abilities, motor abilities, foreknowledge, cognitive and connative characteristics of an individual as well as his familiarity with the theoretical bases of movement technique. Abernethy, Kippers, Mackinnon, Neal and Hanrahm (1997) distinguished between three phases in the process of motor learning: the verbal-cognitive phase during which a new movement structure is first identified and then understood; the 
Optimizing motor skills through classical conditioning theory

associative phase during which several elements of the movement structure are integrated and adapted to the changing circumstances; and the autonomous phase during which movement becomes automatic and results in few errors. During the first phase, a beginner executes a series of unnecessary movements, activates muscles that are not relevant and is unable to bring them into balance. Consequently, his starting position and movement rhythm are incorrect, while his posture is stiff. This phase of motor learning lasts from 15 to 30 hours. In the second, associative phase, the quality of movement improves substantially. Movements are already smoother and more relaxed, while superfluous movements gradually vanish. In the motor part of the central nervous system a notion appears as a motor stereotype. This phase lasts from 3 to 5 months. The third, autonomous phase is that of movement automation, where the individual kinematic and dynamic parameters of movement are optimally integrated. This lasts for several years and is never quite finished. The motor stereotype collapses only in extremely unpredictable circumstances such as fatigue, enormous pressure or stress

Motor learning can be defined as a "set of internal processes associated with practice or experience leading to relatively permanent changes in the capability for skilled behavior." In other words, motor learning is when complex processes in the brain occur in response to practice or experience of a certain skill resulting in changes in the central nervous system that allow for production of a new motor skill. There are three stages in which motor learning occurs:

1. Cognitive Stage- During this initial stage of motor learning, the goal is to develop an overall understanding of the skill. The learner must determine what the objective of the skill is and begin to process environmental factors that will affect their ability to produce the skill. The teacher must do their best to provide an optimal environment for learning, which may mean removing large distracters. During this stage, the learner mostly relies on visual input and trial and error to guide learning. Example: Before a child 
Elvis I. Agbonlahor \& Kelly Osasehia Eghosa masters walking, they will most likely look a bit awkward and will definitely stumble a few times. The reality is that the process of learning how to walk begins way before your child actually takes their first assisted or independent step as they have been visually observing others around them walking and beginning to understand the purpose. So while they make look clumsy during this stage of learning, they are only just beginning to transition from understanding the skill to executing it.

2. Associative Stage - During this stage, the learner begins to demonstrate a more refined movement through practice. Now that the learner has had some practice and has identified various stimuli that may occur, they can focus on "how to do" moving on from the "what to do" in the first stage. Here, visual cues become less important and proprioceptive cues become very important. Proprioceptive cues refer to the learner focusing more on how their body is moving in space and what input is being felt from their joints and muscles. The more practice, the more proprioceptive input the learner receives to aide learning. Therefore, the more practice the better! Example: Let's continue with walking. During the initial clumsy stage your child may demonstrate small, choppy steps, wide base of support, arms up high in a guarded position, and little to no trunk rotation. In this stage, you may see your child taking longer, more controlled steps, narrowing their base of support, and allowing their arms to relax at their sides. These behaviors indicate that your child has moved past the initial stage of learning and has progressed to a more refined movement.

3. Autonomous Stage - During this final stage of learning, the motor skill becomes mostly automatic. Progression to this level of learning allows the learner to perform the skill in any environment with very little cognitive involvement compared to the first stage. Example: Your child will now be able to walk in a predictable environment such as your home or an unpredictable environment such as a crowded birthday party at the park on grass without difficulty. 
Optimizing motor skills through classical conditioning theory

Keep in mind that the learning process can take different lengths of time for every individual and progression can be dependent on a variety of factors such as motivation of the learner, feedback received, environmental stimuli, organization of practice, and the presence of musculoskeletal or neuromuscular impairments. Talk with your therapist for more suggestions to optimize motor learning more specifically for your child.

\section{Interrelationship between Classical Conditioning and Motor Learning}

Most of the emotional responses can be learned through classical conditioning. A negative or positive response comes through the stimulus being paired with. For example, providing the necessary school material for primary school pupils will develop good feelings about school and learning in them while undue punishment might discourage them from attending the school.

Athletes who associate positive physiological responses, such as relaxation and appropriate arousal level, and enhancing emotions, such as joy and satisfaction with their sports and training are more likely to love their sport and come to practice highly motivated to train. This would lead to a high level of performance both in training and competitions. Therefore, to increase motivation, coaches need to condition their athletes to respond positively to not only their sport but the many aspects of their sport, such as training, stretching, conditioning, drill and skill work, and competing. For many athletes, especially young ones, a positive conditioned response is what brings them back each day, each week, each month, and each season.

Athletes need to have positive physiological and psychological responses to their sport. Athletes who have an interest and love for their sport (training and competition) will be engaged and motivated. You can facilitate a positive response by continually pairing positive conditioned stimuli with positive unconditioned 
Elvis I. Agbonlahor \& Kelly Osasehia Eghosa stimuli. A significant way to create a positive response is to facilitate success and mastery during practice, make practice and competition fun, and focus on effort.

In the teaching of motor skills to school children especially at the early stages, it has been observed that there is a general apathy towards learning of physical education most especially the practical aspects of the course. A lot of students have associated the course 'physical education' to undue stress. Classical conditioning can be used to correct this anomaly by associating field work or practical sessions with fun especially at the early stages of student participation. This could involve introducing activities like music, dancing etc. The primary aim of this is to help the students to be conditioned in such a way in which they will associate field work with fun.

\section{Conclusion}

Classical conditioning is a reflexive or automatic type of learning in which a stimulus acquires the capacity to evoke a response that was originally evoked by another stimulus. Motor skill learning which is in the domain of learning of physical skills involve three different stages; the cognitive, associative and autonomous stages. Experts in the fields of sport science, coaching, physical education and other areas have sought for different ways of optimizing motor outcomes among Athletes, school children and in individuals with movement restrictions. Classical conditioning can provide the needed assistance in achieving these much needed goals.

Classical conditioning can be used in helping Athletes who have an unusual fear for opponents or for competitions which could be due to past failures, or any other factor in overcoming their fear and facing their opponents with the needed confidence and courage. It can also be used in assisting school children and new Athletes in developing the needed love and motivation for field work or sports. To the best of the researches knowledge, researches on the 
Optimizing motor skills through classical conditioning theory

effect of classical conditioning on the learning of motor skills are very few.

\section{Recommendations}

1. Classical conditioning should be applied in the teaching of the practical aspects of physical education to students especially in the early stages of their learning. This would help in motivating them and consequently optimizing their motor skill learning and performance.

2. One must be able to practice and master a task effectively before embarking on another one. This means that a student needs to be able to respond to a particular stimulus (information) before he/she can be associated with a new one.

3. Teachers should know how to motivate their students to learn. They should be versatile with various strategies that can enhance effective participation of the students in the teaching-learning activities.

4. Classical conditioning should be used by Coaches and Sports Psychologists in helping Athletes overcome their fear of failure or opponents.

\section{References}

Abernethy, B., Kippers, V., Mackinnon, L., Neal, R., \& Hanrahm, S. (1997). The Biophysical Foundations of Human Movement. Champaign IL: Human Kinetics.

Adams, J. (1976). Issues for a closed-loop theory of motor learning: Motor Control .New York, NY: Academic Press.

Ayeni, O. (1999). Psychology of human learning for Teachers. Ilesa: College of Education 
Elvis I. Agbonlahor \& Kelly Osasehia Eghosa

Burns, R. (1995). The Adult Learner at Work. Sydney: Business and Professional Publishing Ltd.

Watson, J. B., \& Rayner, R. (1920). Conditioned experimental reactions. Journal of Experimental Psychology, 3 (1), $1-14$

Watson, J. B. (1924). Behaviorism. New York: People's Institute Publishing CompanyCherry, Kendra. "What Is a ConditionedResponse?".https://www.verywell.com/whatis-a-conditioned-response-2794974 Retrieved 2017-07-25

Shettleworth, S. J. (2010). Cognition, Evolution, and Behavior (2nd ed.) Oxford Univ. Press

Douglas, L., Brian, H., \& Arthur, B. (2009). Cognitive Psychology. N.p.: n.p,. $\quad 50-53$

Brink, T. L. (2008). Psychology: A Student Friendly Approach. "Unit 6: Learning." . 97-98 